\title{
Editorial: Factors Promoting Development of Fibrosis in Crohn's Disease
}

\author{
Jennifer Bailey* \\ Bristol Veterinary School, University of Bristol, Bristol, United Kingdom
}

Keywords: Crohn's disease, fibrosis, inflammatory bowel disease, strictures, extracellular matrix

\section{Editorial on the Research Topic}

Factors Promoting Development of Fibrosis in Crohn's Disease

Crohn's disease is a form of inflammatory bowel disease, which results in areas of chronic inflammation at any point in the gastrointestinal tract. Intestinal fibrosis is a common but debilitating complication of Crohn's disease for which currently there is no medical treatment. In a number of cases, significant fibrosis is already present at the time of disease diagnosis (1), and $40-70 \%$ of Crohn's disease patients require surgery in the 10 years following diagnosis, with the development of fibrotic strictures being the leading indication for surgery in small bowel disease (2). Fibrosis occurs due to excessive deposition of extracellular matrix (ECM), particularly fibrous collagen, and

OPEN ACCESS

Edited by:

Akira Andoh,

Shiga University of Medical

Science, Japan

Reviewed by:

Hiroshi Nakase,

Kyoto University, Japan Hideki lijima

Osaka University, Japan

*Correspondence:

Jennifer Bailey

j.r.bailey@bristol.ac.uk

Specialty section:

This article was submitted

to Gastroenterology,

a section of the journal

Frontiers in Medicine

Received: 22 August 2017 Accepted: 14 September 2017 Published: 26 September 2017

Citation:

Bailey J (2017) Editorial: Factors Promoting Development of Fibrosis in Crohn's Disease. Front. Med. 4:160. doi: 10.3389/fmed.2017.00160 dysregulated turnover of ECM. Affected tissue becomes hardened and thickened, leading to a loss of function. Fibrogenesis in Crohn's disease is a multifactorial process, influenced by immunological, environmental, genetic, and disease-related factors (3-6). It is not currently known how or why fibrosis develops in such a high population of patients. Fibrosis follows the path of inflammation and has not been seen in areas unaffected by inflammation; however, inflammation is not required to propagate fibrosis once it has been initiated (7). This Research Topic brings together experts in the field to discuss recent advances in the pathogenesis of fibrosis and future perspectives for detection, treatment, and prevention of the condition.

Rogler and Hausmann introduce the topic with a review on the main factors that promote development of fibrosis in Crohn's disease. They discuss new findings that challenge the current dogma in this area and highlight the importance of these when developing novel treatment strategies. It is clear that we need to expand our horizons when we consider which cells contribute to fibrosis and look beyond primary mesenchymal cells. While fibroblasts and smooth muscle cells are significant contributors to fibrosis, increasing evidence suggests a role for epithelial and endothelial cells via epithelial or endothelial-to-mesenchymal transition (8-10). Cytokines have long been known as key players in fibrogenesis, with those produced during the inflammatory response, and found at increased levels in the inflamed IBD gut contributing. In particular, transforming growth factor- $\beta$ (TGF- $\beta$ ) and tumor necrosis factor- $\alpha$ (TNF- $\alpha$ ) have been extensively studied and both stimulate collagen accumulation and mesenchymal cell activation (11). However, these same cytokines are also capable of stimulating both epithelial and endothelialto-mesenchymal transition $(8,12)$ thus their pro-fibrotic effects extend further than originally thought.

The role of cytokines in fibrogenesis has been reviewed in depth in this Research Topic by Curciarello et al. Cytokines such as TGF- $\beta$, IL-1 $\beta$, TNF- $\alpha$, and IL-17A can have a direct effect on mesenchymal cells, preventing their migration away from the site of fibrogenesis, activating them to produce ECM components such as collagen, inducing their proliferation, and stimulating production of tissue inhibitors of matrix metalloproteinases, which prevent the normal breakdown of collagen 
(13-16). Cytokines such as IL-13, IL-6, and IL-33 contribute to fibrogenesis via an indirect effect on mesenchymal cells; for example, they prevent synthesis of MMPs and induce secretion of pro-fibrotic cytokines, such as TGF- $\beta$, by other cell types which are then capable of stimulating collagen deposition (17-20).

There are currently no medical therapies available to treat existing fibrosis. While major advances in surgical strategies have been made in recent years, such as strictureplasty, these procedures are not without risks and many patients prefer to avoid surgery. Early detection and intervention are key to minimizing damage but, as previously mentioned, fibrosis develops silently, demonstrated by the fact that a number of patients will already have significant fibrosis at the time of diagnosis (1). The ability to rapidly screen newly diagnosed patients to predict which already have fibrosis, or are at significant risk of developing fibrosis, could be key to improving outcomes for patients in the future. James and Tyrrell-Price discuss a recent publication on the accuracy of hybrid positron emission tomography (PET)/magnetic resonance-enterography (MR-E) and PET/computed tomography-enterography (CT-E) for the detection of fibrosis in Crohn's disease (21). Differentiation between fibrotic strictures and inflammatory strictures is vital since treatment protocols differ between the two states; inappropriate classification could lead to unnecessary surgery or futile attempts at medical therapy. This study has evaluated these two radiological techniques to determine their effectiveness in predicting which patients will respond to medical therapy and which require surgical intervention. In this small study, PET/ MR-E showed greater success in accurately detecting fibrosis than PET/CT-E; however, while these data are encouraging and indicate that PET/MR-E may be a useful diagnostic tool,

\section{REFERENCES}

1. Pellino G, Sciaudone G, Selvaggi F, Riegler G. Delayed diagnosis is influenced by the clinical pattern of Crohn's disease and affects treatment outcomes and quality of life in the long term: a cross-sectional study of 361 patients in Southern Italy. Eur J Gastroenterol Hepatol (2015) 27:175-81. doi:10.1097/ MEG.0000000000000244

2. Solberg IC, Vatn MH, Hoie O, Stray N, Sauar J, Jahnsen J, et al. Clinical course in Crohn's disease: results of a Norwegian population-based ten-year follow-up study. Clin Gastroenterol Hepatol (2007) 5:1430-8. doi:10.1016/j. cgh.2007.09.002

3. Latella G, Rogler G, Bamias G, Breynaert C, Florholmen J, Pellino G, et al. Results of the 4th scientific workshop of the ECCO (I): pathophysiology of intestinal fibrosis in IBD. JCrohns Colitis (2014) 8:1147-65. doi:10.1016/j. crohns.2014.03.008

4. Latella G, Di Gregorio J, Flati V, Rieder F, Lawrance IC. Mechanisms of initiation and progression of intestinal fibrosis in IBD. Scand J Gastroenterol (2015) 50:53-65. doi:10.3109/00365521.2014.968863

5. Chang CW, Wong JM, Tung CC, Shih IL, Wang HY, Wei SC. Intestinal stricture in Crohn's disease. Intest Res (2015) 13:19-26. doi:10.5217/ir.2015.13.1.19

6. Cleynen I, Boucher G, Jostins L, Schumm LP, Zeissig S, Ahmad T, et al. Inherited determinants of Crohn's disease and ulcerative colitis phenotypes: a genetic association study. Lancet (2016) 387:156-67. doi:10.1016/ S0140-6736(15)00465-1

7. Rieder F, Fiocchi C, Rogler G. Mechanisms, management, and treatment of fibrosis in patients with inflammatory bowel diseases. Gastroenterology (2017) 152:340-50.e6. doi:10.1053/j.gastro.2016.09.047

8. Rieder F, Kessler SP, West GA, Bhilocha S, de la Motte C, Sadler TM, et al. Inflammation-induced endothelial-to-mesenchymal transition: a novel current low availability and high cost prohibit its use as a routine screening procedure.

Genetic factors are likely to play in a role in the susceptibility of an individual to developing fibrotic disease. If these factors can be determined, it could unlock new treatment pathways or be used to predict the course of disease in newly diagnosed patients. Verstockt and Cleynen have reviewed the current knowledge of genetic influences on fibrogenesis in Crohn's disease. Several genes have been implicated in the pathogenesis of Crohn's disease; however, very few have been identified as independent risk factors for developing fibrostenotic disease. The most studied genetic predictor for fibrotic disease is nucleotide-binding oligomerization domain-containing protein 2 (NOD2). While a link has been found between NOD2 and fibrostenotic disease in a number of studies (22-26), other groups have been unable to find this association $(6,27)$; therefore, the picture is unclear, and NOD2 genotyping in all patients is unjustified at present.

A major challenge for the future will be to develop novel medical therapies to treat and prevent fibrosis to reduce reliance on surgical techniques. Traditionally, fibrosis has been thought of as irreversible; however, this may not be the case; fibrosis has been shown to be reduced following strictureplasty (28), giving hope for new treatment strategies. Excellent progress has been made in the field of surgery but continuation of investigation into the processes that stimulate fibrogenesis and development of animal models with which to trial candidate therapies are critical if we are to achieve the holy grail that is medical treatment of fibrosis.

\section{AUTHOR CONTRIBUTIONS}

JB conceived and wrote the manuscript alone.

mechanism of intestinal fibrosis. Am J Pathol (2011) 179:2660-73. doi:10.1016/ j.ajpath.2011.07.042

9. Rieder F, Fiocchi C. Intestinal fibrosis in IBD - a dynamic, multifactorial process. Nat Rev Gastroenterol Hepatol (2009) 6:228-35. doi:10.1038/nrgastro. 2009.31

10. Rieder F, Brenmoehl J, Leeb S, Scholmerich J, Rogler G. Wound healing and fibrosis in intestinal disease. Gut (2007) 56:130-9. doi:10.1136/gut. 2006.090456

11. Speca S, Giusti I, Rieder F, Latella G. Cellular and molecular mechanisms of intestinal fibrosis. World J Gastroenterol (2012) 18:3635-61. doi:10.3748/wjg. v18.i28.3635

12. Flier SN, Tanjore H, Kokkotou EG, Sugimoto H, Zeisberg M, Kalluri R. Identification of epithelial to mesenchymal transition as a novel source of fibroblasts in intestinal fibrosis. J Biol Chem (2010) 285:20202-12. doi:10.1074/ jbc.M110.102012

13. Graham MF, Bryson GR, Diegelmann RF. Transforming growth factor beta 1 selectively augments collagen synthesis by human intestinal smooth muscle cells. Gastroenterology (1990) 99:447-53. doi:10.1016/0016-5085(90)91028-5

14. Graham MF, Willey A, Adams J, Yager D, Diegelmann RF. Interleukin 1 beta down-regulates collagen and augments collagenase expression in human intestinal smooth muscle cells. Gastroenterology (1996) 110:344-50. doi:10.1053/ gast.1996.v110.pm8566579

15. Drygiannakis I, Valatas V, Sfakianaki O, Bourikas L, Manousou P, Kambas K, et al. Proinflammatory cytokines induce crosstalk between colonic epithelial cells and subepithelial myofibroblasts: implication in intestinal fibrosis. J Crohns Colitis (2013) 7:286-300. doi:10.1016/j.crohns.2012.04.008

16. Biancheri P, Pender SL, Ammoscato F, Giuffrida P, Sampietro G, Ardizzone S, et al. The role of interleukin 17 in Crohn's disease-associated intestinal fibrosis. Fibrogenesis Tissue Repair (2013) 6:13. doi:10.1186/1755-1536-6-13 
17. Bailey JR, Bland PW, Tarlton JF, Peters I, Moorghen M, Sylvester PA, et al. IL-13 promotes collagen accumulation in Crohn's disease fibrosis by downregulation of fibroblast MMP synthesis: a role for innate lymphoid cells? PLoS One (2012) 7:e52332. doi:10.1371/journal.pone.0052332

18. Fichtner-Feigl S, Strober W, Kawakami K, Puri RK, Kitani A. IL-13 signaling through the IL-13alpha2 receptor is involved in induction of TGF-beta1 production and fibrosis. Nat Med (2006) 12:99-106. doi:10.1038/nm1332

19. Li C, Iness A, Yoon J, Grider JR, Murthy KS, Kellum JM, et al. Noncanonical STAT3 activation regulates excess TGF-betal and collagen I expression in muscle of stricturing Crohn's disease. J Immunol (2015) 194:3422-31. doi:10.4049/jimmunol.1401779

20. Masterson JC, Capocelli KE, Hosford L, Biette K, McNamee EN, de Zoeten EF, et al. Eosinophils and IL-33 perpetuate chronic inflammation and fibrosis in a pediatric population with stricturing Crohn's ileitis. Inflamm Bowel Dis (2015) 21:2429-40. doi:10.1097/MIB.0000000000000512

21. Pellino G, Nicolai E, Catalano OA, Campione S, D’Armiento FP, Salvatore M, et al. PET/MR versus PET/CT imaging: impact on the clinical management of small-bowel Crohn's disease. J Crohns Colitis (2016) 10:277-85. doi:10.1093/ ecco-jcc/jjv207

22. Cleynen I, Gonzalez JR, Figueroa C, Franke A, McGovern D, Bortlik M, et al. Genetic factors conferring an increased susceptibility to develop Crohn's disease also influence disease phenotype: results from the IBDchip European Project. Gut (2013) 62:1556-65. doi:10.1136/gutjnl-2011-300777

23. Annese V, Lombardi G, Perri F, D'Inca R, Ardizzone S, Riegler G, et al. Variants of CARD15 are associated with an aggressive clinical course of Crohn's disease - an IG-IBD study. Am J Gastroenterol (2005) 100:84-92. doi:10.1111/j.1572-0241.2005.40705.x

24. Lakatos PL, Lakatos L, Szalay F, Willheim-Polli C, Osterreicher C, Tulassay Z, et al. Toll-like receptor 4 and NOD2/CARD15 mutations in Hungarian patients with Crohn's disease: phenotype-genotype correlations. World J Gastroenterol (2005) 11:1489-95. doi:10.3748/wjg.v11.i10.1489

25. Abreu MT, Taylor KD, Lin YC, Hang T, Gaiennie J, Landers CJ, et al. Mutations in NOD2 are associated with fibrostenosing disease in patients with Crohn's disease. Gastroenterology (2002) 123:679-88. doi:10.1053/gast. 2002.35393

26. Helio T, Halme L, Lappalainen M, Fodstad H, Paavola-Sakki P, Turunen U, et al. CARD15/NOD2 gene variants are associated with familially occurring and complicated forms of Crohn's disease. Gut (2003) 52:558-62. doi:10.1136/ gut.52.4.558

27. Baptista ML, Amarante H, Picheth G, Sdepanian VL, Peterson N, Babasukumar U, et al. CARD15 and IL23R influences Crohn's disease susceptibility but not disease phenotype in a Brazilian population. Inflamm Bowel Dis (2008) 14:674-9. doi:10.1002/ibd.20372

28. Yamamoto T, Fazio VW, Tekkis PP. Safety and efficacy of strictureplasty for Crohn's disease: a systematic review and meta-analysis. Dis Colon Rectum (2007) 50:1968-86. doi:10.1007/s10350-007-0279-5

Conflict of Interest Statement: The author declares that the research was conducted in the absence of any commercial or financial relationships that could be construed as a potential conflict of interest.

Copyright (C) 2017 Bailey. This is an open-access article distributed under the terms of the Creative Commons Attribution License (CC BY). The use, distribution or reproduction in other forums is permitted, provided the original author(s) or licensor are credited and that the original publication in this journal is cited, in accordance with accepted academic practice. No use, distribution or reproduction is permitted which does not comply with these terms. 